\title{
Antioxidant Activity of the Extracts from Jatropha curcas Fruit and Its Correlation with Total Phenolic Content
}

\author{
KANDA SAOSOONG, ISARAWAT LITTHANAPONGSATORN \\ and CHALERM RUANGVIRIYACHAI* \\ Department of Chemistry, Faculty of Science, Khon Kaen University, Khon \\ Kaen 40002, Thailand. \\ *Corresponding author E-mail: chal_ru@kku.ac.th \\ http://dx.doi.org/10.13005/ojc/320237
}

(Received: March 26, 2016; Accepted: April 05, 2016)

\begin{abstract}
The correlation between antioxidant activity and total phenolic content of the crude extract from J. curcas fruit were evaluated. The crude extract was obtained by extracting with selected solvent and fractionated with a hydrophilic lipophilic balanced (HLB) cartridge. The total phenolic content of crude extract with Folin-Ciocalteu method gave the content at $7.04 \pm 0.10 \mathrm{mg} \mathrm{GAE} / \mathrm{g}$ of extract and $0.22-18.61 \mathrm{mg} \mathrm{GAE} / \mathrm{g}$ of extract for its fraction. The antioxidant activity of crude extract was $270.98 \pm 0.59 \mu \mathrm{mol} F e / g$ of extract with Phen method and the extract gave $\mathrm{IC}_{50}$ at $14.09 \pm 0.05 \mathrm{mg} /$ $\mathrm{mL}$ with DPPH method. A good correlation among antioxidant activity and total phenolic content of both methods were observed. Furthermore, the methanolic fraction $\left(F_{5}\right)$ showed highest antioxidant activity with $\mathrm{IC}_{50}$ at $0.04 \pm 0.02 \mathrm{mg} / \mathrm{mL}$ as the study of DPPH method and $207.53 \pm 2.58 \mu \mathrm{mol} \mathrm{Fe} / \mathrm{g}$ of extract as the study of Phen method.
\end{abstract}

Keywords: Jatropha curcas fruit, Total phenolic content, Antioxidant activity, DPPH method, Phen method, Pearson correlation.

\section{INTRODUCTION}

Several types of medicinal plants have proven to be an effective source for both medicinal folklore and the development of drugs industry in currently. Bioactive compounds are also known to produce from numerous types of medicinal plants ${ }^{1-3}$. These compounds demonstrate antioxidant, antibacterial, antiviral, anti-inflammatory and anticancer properties as described in previous studies $^{4-6}$. Especially, phenolic compounds possess the effect of antioxidant activities with scavenging free radicals, reducing activities and chelating of metal ${ }^{7,8}$. In currently, the used of synthetic antioxidant compounds in the industrial processing are increased ${ }^{9}$. Nevertheless, these synthetic compounds have been considered the carcinogenic effect ${ }^{10}$. Consequently, more interest focuses on the importance of natural bioactive compounds derived from plants in currently. 
Jatropha curcas (J.curcas) is a multipurpose plant in Euphorbiaceae family, has a lot of economic significance because of its industrial and medicinal values. The researches of $J$. curcas plant in Thailand are mainly regarding the improvement of the quality of biodiesel production source, genetic diversity analysis and also the analysis of phorbol ester in the plants ${ }^{11-13}$. However, the studies of other utilization of the several parts of $J$. curcas plant in Thailand are still lacking. Various parts of J. curcas plant have been studied about phytochemical compound identification for searching new natural bioactive compounds in previously reported ${ }^{14}$. Consequently, the studies about finding natural antioxidant compounds from other parts of $J$. curcas are important for the further escalation value of this plant.

As the antioxidant activity examination, DPPH and Phen method are mostly used for study this activity with radical scavenging and reducing power properties, respectively. Several reports described that phenolic compounds were main substances that have influence of antioxidant activity in plant extracts and also the correlation of total phenolic contents and antioxidant activity were studied ${ }^{7,15}$. The correlation of antioxidant activity and phenolic contents may be explained by different reasons, such as all compounds from total phenolic contents not collaborate to demonstrate the antioxidant activity. Consequently, the present study is interested in the correlation of antioxidant activity with difference test methods and phenolic compounds containing in $\mathrm{J}$. curcas fruit extracts. Therefore, the objectives of this research were to evaluate the bioactive properties of the extracts of $J$. curcas fruit by determining total phenolic contents and antioxidant activity with difference of test methods including DPPH and Phen methods.

\section{MATERIALS AND METHODS}

The materials of $J$. curcas fruits were kindly contributed from Khon Kaen Field Crops Research Center (KKFCRC) Khon Kaen Province, Thailand. The green fruits of $J$. curcas were selected for this study. Folin-Ciocalteu reagent for total phenolic content evaluation was purchased from Merck (Germany). As the extraction study, methanol, ethanol, acetone, hexane, dichloromethane, chloroform and ethyl acetate were purchased from Carla Erba (Italy). Additionally, an Oasis ${ }^{\circledR}$ hydrophilic lipophilic balanced (HLB) cartridge (6 $\mathrm{mL}, 500 \mathrm{mg}$ ) was obtained from Waters (Ireland). 2, 2-diphenyl-1-picryhydrazyl (DPPH), gallic acid, 1, 10phenanthroline were purchased from Sigma-Aldrich (Switzerland). 2, 6-di-tert-butyl-4-methylphenol (BHT) was achieved from Acros Organic (USA). Ferric chloride, sodium carbonate, sodium hydroxide, and ferrous sulfate heptahydrate were obtained from Carlo Erba (Italy).

\section{Extraction of $\boldsymbol{J}$. curcas fruit}

The suitable type of solvent for the extraction of $J$. curcas fruit was evaluated. Briefly, $2 \mathrm{~g}$ of the crushed $J$. curcas dried sample was extracted three times with $25 \mathrm{~mL}$ of $60 \%(\mathrm{v} / \mathrm{v})$ extracted solvent by shaken with an orbital shaker (Yamato Scientific, Japan) at $150 \mathrm{rpm}$ at ambient temperature $\left(30^{\circ} \mathrm{C}\right)$ for $2 \mathrm{~h}$. And then, the extract was filtered through a Whatman No. 1 filter paper (USA). After that, the solvent in the filtrate was removed by using a rotary vacuum evaporator and then brown color of crude extracts was achieved. The selected solvent type considered from the crude extract that show high quantity of total phenolic content. The achieved crude extracted solution was further isolated by loading through a HLB cartridge and eluted with $25 \mathrm{~mL}$ of hexane, dichloromethane, chloroform, ethyl acetate and methanol, respectively. Finally, the solvent of each fraction was removed to obtain the remaining defined as $F_{1}, F_{2}, F_{3}, F_{4}$ and $F_{5}$, respectively.

\section{Determination of total phenolic content (TPC)}

Firstly, $300 \mu \mathrm{L}$ of the extracts or standard solutions of gallic acid were mixed with $1.5 \mathrm{~mL}$ of 10 fold diluted Folin-Ciocalteu reagent. Subsequently, $3.0 \mathrm{~mL}$ of $7.5 \%(\mathrm{w} / \mathrm{v})$ sodium carbonate was added. These mixtures were then incubated in the dark condition at ambient temperature $\left(30^{\circ} \mathrm{C}\right)$ for 30 minutes. The absorbance of these reaction mixtures were recorded at $765 \mathrm{~nm}$ using a UV-Visible spectrophotometer (Agilent model 8453, Germany). The TPC was attained from a regression equation $\left(R^{2}=0.9973\right)$, and reported as gallic equivalent (GAE) in mg per $1 \mathrm{~g}$ of the extract. 


\section{Evaluation of antioxidant activity}

\section{2, 2-diphenyl-1-picryhydrazyl (DPPH) method}

The tested samples or standard BHT were mixed with $100 \mu \mathrm{M}$ DPPH solution and adjusted volume into $10 \mathrm{~mL}$ with methanol. These mixtures were then incubated in the dark condition at $25^{\circ} \mathrm{C}$ for $30 \mathrm{~min}$. The absorbance of control, sample and $\mathrm{BHT}$ were recorded at $517 \mathrm{~nm}$ by using a UV-Vis spectrophotometer. The percentage inhibition was calculated as equation 1 . The results were reported as $\mathrm{IC}_{50}$ value, which obtained from the plotting of \% inhibition versus concentration of the extracts.

$\%$ Inhibition $=\frac{\left(A_{517} \text { control }-A_{517} \text { sample }\right)}{A_{517} \text { control }} \times 100$

\section{Phenanthroline (Phen) method}

The extract, $0.2 \%(\mathrm{w} / \mathrm{v})$ of ferric chloride and $0.5 \%(\mathrm{w} / \mathrm{v})$ of 1,10 -phennanthroline solution was mixed and adjusted volume to $10 \mathrm{~mL}$ with methanol. The achieved solutions were mixed and left at ambient temperature $\left(30^{\circ} \mathrm{C}\right)$ in the dark condition for $30 \mathrm{~min}$. The absorbance of mixture was measured at $510 \mathrm{~nm}$ against blank by using a UVVis spectrophotometer. Working solutions of ferrous sulfate in the range of $100-700 \mu \mathrm{moL} / \mathrm{L}$ were used to prepare for calibration curve. The results were expressed as amount of antioxidant activity on $\mu \mathrm{moL}$ of Fe per $1 \mathrm{~g}$ extract.

\section{Statistical analysis}

Statistical analysis was carried out using Microsoft Corporation Computer Excel Program
(USA). All experiments were performed in triplicated. The obtained antioxidant results were presented as mean \pm standard deviation (SD). The Pearson correlation test of antioxidant activity and total phenolic content were done with SPSS Statistics 19 Program.

\section{RESULTS AND DISCUSSION}

\section{Extraction of $J$. curcas fruit}

TPC of each extract was determined using Folin-Ciocalteu method according to Fu et al (2014) with minor modification ${ }^{2}$. The chemical reaction depends on the reduction of Folin-Ciocalteu reagent (FCR) by phenolic compound to a mixture of blue oxides, which have a maximal absorption at $765 \mathrm{~nm}$ using a spectrophotometer. The suitable extracting solvent was evaluated by comparison the quantity of TPC of each extract. The results of TPC of crude extracts with different extracted solvent showed in Fig. 1. It was observed that methanol has higher efficient for the extraction than ethanol and acetone with TPC at $6.77 \pm 0.34,5.59 \pm 0.14,4.66 \pm 0.43$ $\mathrm{mg} \mathrm{GAE} / \mathrm{g}$ of the extract, respectively. As this result, it may be due to the different phenolic content with different polarity. Therefore, it was suggested that solvents used affected to the total phenolic content of the extracts. Consequently, methanol was chosen as the extracting solvent for the further study.

\section{Total phenolic content (TPC) of the extracts}

TPC of the crude methanolic extracts were evaluated to establish their effect on antioxidant activity and also the correlation of them. This content

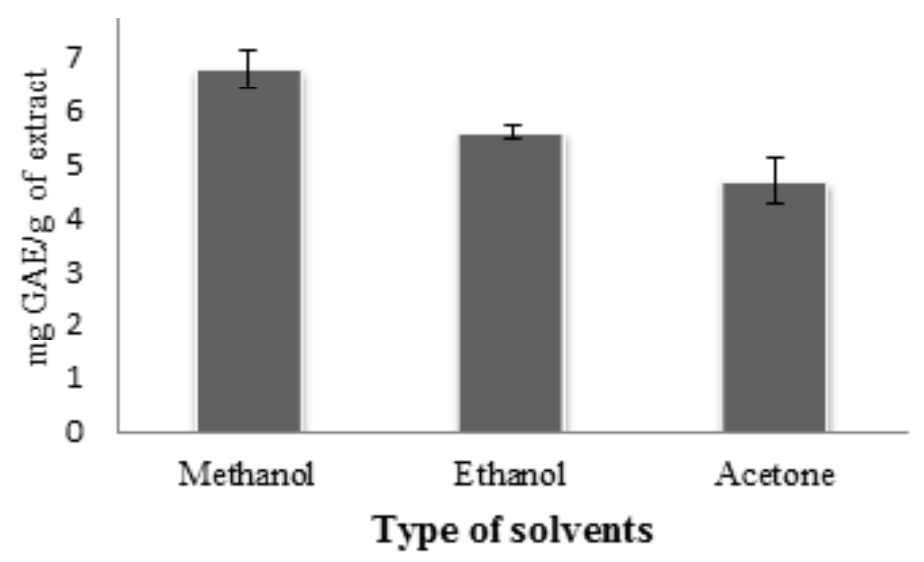

Fig. 1: Effect of extracting solvents for phenolic extraction 
was determined as $\mathrm{mg}$ of gallic acid equivalent (GAE)/g of the extract by using the regression equation from the calibration curve of gallic acid standard in the range of $25-250 \mu \mathrm{g} / \mathrm{mL}$ (Fig. 2). TPC of crude methanolic extracts was $7.04 \pm 0.10 \mathrm{mg}$ GAE/g of the extract and the TPC of the fractions isolated from HLB cartridge were also shown in Table 1. It was found that the extracts contain TPC value in the range of $0.22-18.61 \mathrm{mg} \mathrm{GAE} / \mathrm{g}$ of the extract. It was observed that the highest TPC value present in methanol fraction $\left(\mathrm{F}_{5}\right)$. Furthermore, TPC of difference crude methanolic concentrations were determined against the antioxidant activity of each concentration of extract for the study of their correlation.

\section{Antioxidant activity of the extracts}

As some of previously reported, the evaluation of antioxidant activity by more than one method was reasonable because of different methods

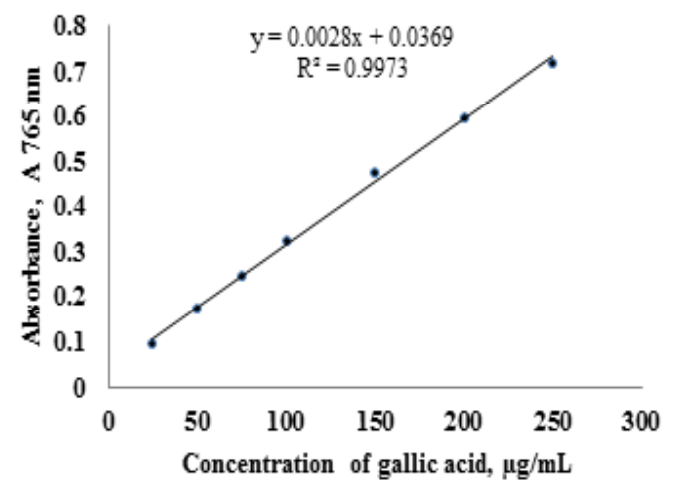

Fig. 2: Calibration curve of gallic acid standard in Folin-ciocalteu method

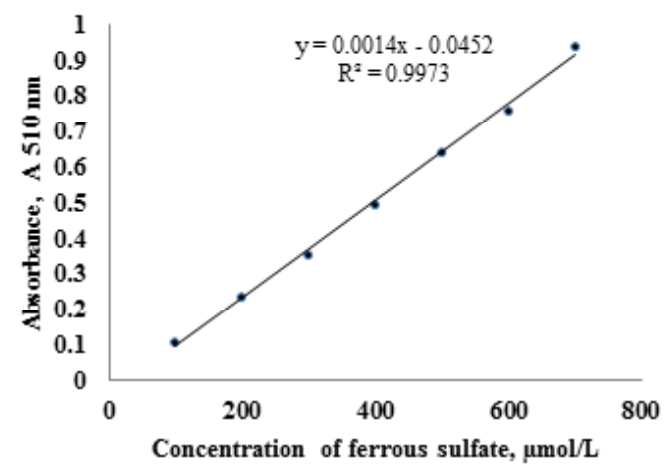

Fig. 3: Calibration curve of ferrous sulfate obtained from Phen method assess different characteristics of antioxidant compounds ${ }^{16}$. In this study, antioxidant activity of the extracts from $\mathrm{J}$. curcas fruit was individually evaluated using two common methods with different mechanisms including DPPH and Phen method. As the results of Phen method, calibration curve of ferrous sulphate in the range of $100-700 \mu \mathrm{moL} / \mathrm{L}$ was obtained (Fig. 3). The crude methanolic extract showed antioxidant activity at $270.98 \pm 0.59 \mu \mathrm{molFe} / \mathrm{g}$ of the extract, as shown in Table 1.

The scavenging activity of the crude methanolic extracts on DPPH was also shown in Table 1. DPPH is a stable radical with a maximum absorbance at $517 \mathrm{~nm}$. The ability of an antioxidant component in the extracts to scavenge DPPH was evaluated on the basis of their $I_{50}$ value, defined as the concentration of sample to decrease the absorbance at $517 \mathrm{~nm}$ of DPPH solution to half of its initial value. The lower $I_{50}$ value indicated a strong ability of the component in the extracts to act as DPPH scavengers while the higher $\mathrm{IC}_{50}$ value indicates a lower scavenging activity of the extract. The results showed that the crude methanolic extracts gave $\mathrm{IC}_{50}$ at $14.09 \pm 0.05 \mathrm{mg} / \mathrm{mL}$ (Table 1), which can be determined by the plotting of $\%$ inhibition and concentration of extracts as shown in Fig. 4. Moreover, the fractions obtained from HLB separation gave highly antioxidant activity especially methanol fraction $\left(F_{5}\right)$ with both test methods, as shown in Table 1. It is noteworthy that the active compound may contain highly in this fraction. However, the characterizations by using further technique such as GC-MS or HPLC-MS may be

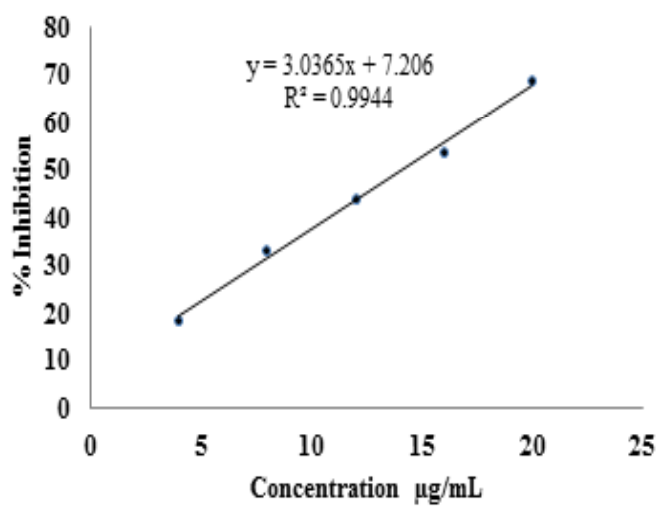

Fig. 4: \% Inhibition of DPPH method 
required for identify the type of interested antioxidant compounds which contain in the extracts.

As antioxidant activity tests with two above methods, the results showed that the extracts from $\mathrm{J}$. curcas fruit had a higher both total phenolic content and antioxidant activity than $\mathrm{J}$. curcas seed oil in our previous work ${ }^{17}$. Consequently, these results suggested that $J$. curcas fruit has highly potential as effective natural antioxidant sources. However, in order to approve that antioxidant activity of the $\mathrm{J}$. curcas crude methanolic extracts is mainly as results from the content of some phenolic compounds, the correlation coefficient of antioxidant activity and total phenolic content were determined, as shown in Fig 5. The results show that the increasing of antioxidant activity correlate with total phenolic content with correlation coefficient at 0.959 and 0.875 , as the study of Phen and DPPH method, respectively.

It may be due to the present of some phenolic compounds such as methyl-3-(3,5-di-tert-butyl-4-

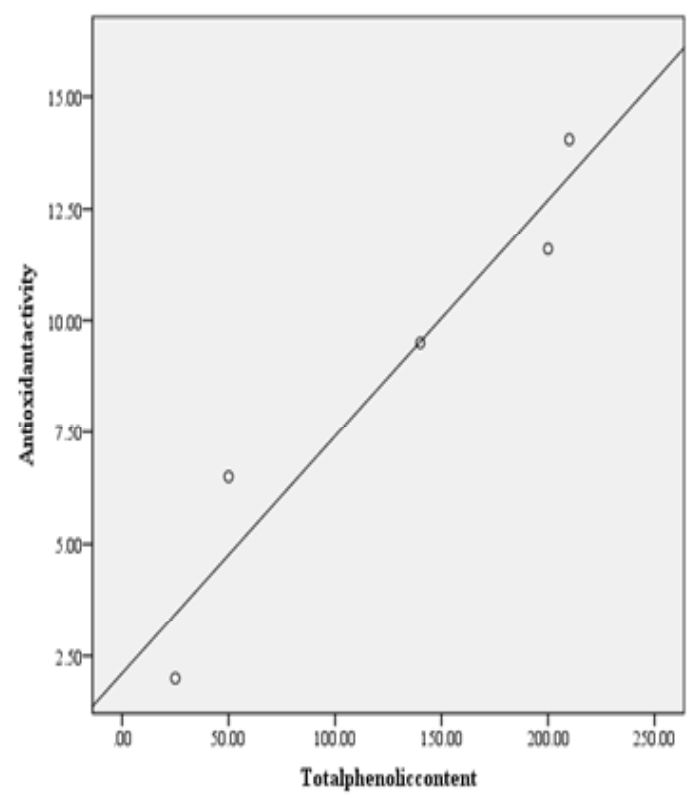

Fig. 5: Pearson correlation plot between total phenolic content and antioxidant activity of Phen method

Table 1: Total phenolic content and antioxidant activity of the extracts of $J$. curcas fruit

\begin{tabular}{lccc}
\hline & $\begin{array}{c}\text { Total phenolic } \\
\text { The }\end{array}$ & \multicolumn{2}{c}{ Antioxidant activity } \\
\cline { 3 - 4 } extracts & $\begin{array}{c}\text { content } \\
\text { (mg GAE/g } \\
\text { extract) }\end{array}$ & $\begin{array}{c}\text { Phen assay } \\
(\boldsymbol{\mu m o l ~ F e / g ~ e x t r a c t ) ~}\end{array}$ & $\begin{array}{c}\text { DPPH assay } \\
\text { as IC50 }(\mathbf{m g} / \mathbf{m L})\end{array}$ \\
\hline Crude methanolic & $7.04 \pm 0.10$ & $270.98 \pm 0.59$ & $14.09 \pm 0.05$ \\
Hexane, $\mathrm{F}_{1}$ & $0.22 \pm 0.08$ & $1.34 \pm 0.21$ & $15.40 \pm 2.06$ \\
Dichloromethane, $\mathrm{F}_{2}$ & $1.04 \pm 0.14$ & $9.50 \pm 1.25$ & $7.40 \pm 1.56$ \\
Chloroform, $\mathrm{F}_{3}$ & $5.03 \pm 0.24$ & $33.95 \pm 4.02$ & $1.06 \pm 0.41$ \\
Ethyl acetate, $\mathrm{F}_{4}$ & $1.86 \pm 0.43$ & $50.68 \pm 3.42$ & $4.90 \pm 1.13$ \\
Methanol, $\mathrm{F}_{5}$ & $18.61 \pm 0.30$ & $207.53 \pm 2.58$ & $0.04 \pm 0.02$ \\
\hline
\end{tabular}

hydroxyphenyl) propionate according to the studied of Tongpoothorn et al. (2012) and also 5,4'-dihydroxy-3, 7, 3'-trimethoxyflavone, 5, 3', 4'-trihydroxy-3,7dimethoxyflavone, 3-O-methylquercetin, 5, 6, 7-trimethoxycoumarin, tomentin, isoscopoletin, omega-hydroxypropioquaiacone, coniferaldehyde, 3, 5-dihydroxy-4-methoxybenzaldehyde, vanillic acid, isovanillin, 4-hydroxybenzaldehyde, cimifugin and (E)-3-hydroxy-5-methoxy-stilbene according to the studied of Jun and Xu (2012) $)^{17,18}$. Additionally, the synergism between the antioxidant compounds in the extracts made the antioxidant activity dependent on concentration or the structure of the containing compound and the interaction between the antioxidant compounds. It can be seen that these results of the relationship between phenolic content and antioxidant property of this plant agree with this characteristic of some plant from previously reported $^{19,20}$. 


\section{CONCLUSIONS}

The crude methanolic extracts of $J$. curcas fruit exhibited good antioxidant activity determined by using the Phen and DPPH methods. And also, this activity correlates with the total phenolic content as the study of Folin-Ciocalteu method. High correlation among antioxidant activity and total phenolic content of both antioxidant methods were achieved. And also, the extracts obtained from HLB separation show highly amount of total phenolic content and antioxidant activity especially methanol fraction. Therefore, the compounds present in the $J$. curcas fruit extracts can be introduced as potential candidate for natural antioxidant activity sources. The findings of the study are useful for the further research to identify, isolate and characterize the specific compounds which is responsible for higher antioxidant activity. This study contributes a good foundation for the utilization of $J$. curcas fruit as a source of antioxidant compounds.

\section{ACKNOWLEDGEMENTS}

The authors would like to gratefully acknowledge the National Research University Project of Thailand, Office of the Higher Education Commission through the Biofuel Cluster Khon Kaen University, Thailand, for financial support in this research. All supporting instruments and experiment facilities from Department of Chemistry, Faculty of Science, Khon Kaen University, Thailand, is also appreciatively acknowledged.

\section{REFERENCES}

1. Sabandar, C.W.; Ahmat, N.; Jaafar, F.M.; Sahidin, I. Medicinal property, phytochemistry and pharmacology of several Jatropha species (Euphorbiaceae): A review. Phytochemistry, 2013, 85, 7-29.

2. Fu, R.; Zhang, Y.; Guo, Y.; Liu, F.; Chen, F. Determination of phenolic contents and antioxidant activities of extracts of Jatropha curcas L. seed shell, a by-product, a new source of natural antioxidant. Ind. Crop. Prod., 2014, 58, 265-270.

3. El-Baz, F.K.; Ali, F.F.; El-Rahman, A.A.; Aly, H.F.; Saad, S.A.; Mohamed, A.A. HPLC evaluation of phenolic profile, and antioxidant activity of different extracts of Jatropha curcas leaves. Int. J. Pharm. Sci. Rev. Res., 2014, 29(1), 203-210.

4. Oskoueian, E.; Abdullah, N.; Ahmad, S.; Saad, W.Z.; Omar, A.R.; Ho, Y.W. Bioactive compounds and biological activities of Jatropha curcas L. kernel meal extract. Int. J. Mol. Sci., 2011, 12(9), 5955-5970.

5. Kumar, A.; Sharma, S. An evaluation of multipurpose oil seed crop for industrial uses (Jatropha curcas L.) A review. Ind. Crops. Prod., 2008, 28(1), 1-10.

6. Abdul-Hafeez, E.Y.; Karamova, N.S.; Ilinskaya, O.N. Antioxidant activity and total phenolic compound content of certain medicinal plants.
Int. J. Biosci., 2014, 5(9), 213-222.

7. Terpinc, P.; Ėeh, B.; Ulrih, N.P.; Abramoviè, H. Studies of the correlation between antioxidant properties and the total phenolic content of different oil cake extracts. Ind. Crop. Prod., 2012, 39, 210-217.

8. Huang, D.; Ou, B., Prior, R.L. The chemistry behind antioxidant capacity assays. J. Agric. Food Chem., 2005, 53(6), 1841-1856.

9. Marina, Z.; Nariham, A. Quantification of total phenolic compound and in vitro antioxidant potential of fruit peel extracts. Int. Food Res. J., 2014, 21(5), 1925-1929.

10. Dung, N.T.; Kim, J.M.; Kang, S.C. Chemical composition, antimicrobial and antioxidant activities of the essential oil and the ethanol extract of Cleistocalyx operculatus (Roxb.) Merr and Perry buds. Food Chem. Toxicol., 2008, 46(12), 3632-3639.

11. Saetae, D.; Suntornsuk, W. Variation of phorbol ester contents in Jatropha curcas from different provinces in Thailand and the application of its seed cake for starter broiler diets. Am-Euras. J. Agric. \& Environ. Sci., 2010, 8(5), 497-501.

12. Supamathanon, N.; Wittayakun, J.; Prayoonpokarach, S. Properties of Jatropha seed oil from Northeastern Thailand and its transesterification catalyzed by potassium 
supported on NaY zeolite. J. Ind. Eng. Chem. 2011, 17(2), 182-185.

13. Kanchanaketu, T.; Sangduen, N.; Toojinda, T.; Hongtrakul, V. Genetic diversity analysis of Jatropha curcas L. (Euphorbiaceae) based on methylation-sensitive amplification polymorphism. Genet. Mol. Res. 2012, 11(2), 944-955.

14. Nithiyanantham, S.; Siddhuraju, P.; Francis, G. A promising approach to enhance the total phenolic content and antioxidant activity of raw and processed Jatropha curcas L. kernel meal extracts. Ind.Crop. Prod., 2013, 43, 261-269.

15. Arranz, S.; Cert, R.; Pérez-Jiménez, J.; Cert, A.; Saura-Calixto, F. Comparison between free radical scavenging capacity and oxidative stability of nut oils. Food Chem., 2008, 110(4), 985-990.

16. Mohsen, S.M.; Ammar, A.S.M. Total phenolic contents and antioxidant activity of corn tassel extracts. Food Chem., 2009, 112(3), 595-598.

17. Tongpoothorn, W.; Chanthai, S.; Sriuttha, M.; Saosoong, K.; Ruangviriyachai, C. Bioactive properties and chemical constituents of methanolic extract and its fractions from Jatropha curcas oil. Ind Crop. Prod., 2012, 36(1), 437-444.

18. Jun, J.; Xu, N. Phenolic compounds from Jatropha curcas. China J. Chin.Mat. Med., 2012, 37(20), 3074-3077.

19. Erbil, N.; Duzguner, V.; Durmuskahya, C.; Alan, Y. Antimicrobial and antioxidant effects of some Turkish fodder plants belongs to Fabaceae family (Vicia villosa, Trifolium ochroleucum and Onobrychis altissima). Orient. J. Chem., 2015, 31(3), 1263-1268.

20. Rattanakom, S.; Yasurin, P. Chemical profiling of Centella asiatica under different extraction solvents and its antibacterial activity, antioxidant activity. Orient. J. Chem., 2015, 31(4), 2453-2459. 